\title{
Correlations between fracture load of zirconia implant supported single crowns and mechanical properties of restorative material and cement
}

\author{
Nadja ROHR ${ }^{1}$, Sabrina MÄRTIN² and Jens FISCHER ${ }^{1}$ \\ ${ }^{1}$ Division of Dental Materials and Engineering, Department of Reconstructive Dentistry and Temporomandibular Disorders, University Center for \\ Dental Medicine, University of Basel, Hebelstrasse 3, 4056 Basel, Switzerland \\ ${ }^{2}$ VITA Zahnfabrik, Spitalgasse 3, 79713 Bad Säckingen, Germany \\ Corresponding author, Nadja ROHR; E-mail: nadja.rohr@unibas.ch
}

Zirconia implants that were restored with veneered zirconia displayed severe chipping rates of the restorations in clinical studies. Purpose of this study was to evaluate the fracture load of different zirconia implant supported monolithic crown materials (zirconia, alumina, lithium disilicate, feldspar ceramic and polymer-infiltrated ceramic) cemented with various cements (Harvard LuteCem SE, Harvard Implant Semi-permanent, Multilink Automix, VITA Adiva F-Cem). Flexural strength and fracture toughness of crown materials and compressive strength of the cements were measured. Fracture load values of crowns fabricated from lithium disilicate, feldspar ceramic and polymer-infiltrated ceramic were increased when cement with high compressive strength was used. Fracture loads for zirconia and alumina crowns were not influenced by the cement. Flexural strength and fracture toughness of the ceramics correlated linearly with the respective fracture load when using adhesive cement with high compressive strength. To achieve sufficient fracture load values, cementation with adhesive cement is essential for feldspar and polymer-infiltrated ceramic.

Keywords: Fracture load, Fracture toughness, Flexural strength, Resin composite cement, Zirconia implant

\section{INTRODUCTION}

Implants made from zirconia may be considered as a promising metal free alternative to the well-established titanium implants ${ }^{1-6)}$. Compared to the natural tooth with its periodontal ligament, the implant-bone interface is rigid. Therefore, the transmission of intraoral forces from the suprastructure to the implant is more intense than for human teeth. When zirconia implants were restored with veneered zirconia crowns, chipping fractures were recorded ${ }^{7)}$, indicating stresses higher than the strength of the veneering ceramic. A monolithic crown material with a low modulus of elasticity ${ }^{8}$ might compensate the ancylotic connection between implant and bone as well as the high modulus of elasticity of the implant material. This might reduce the total load on the implant and surrounding bone.

To predict clinical behavior of restorations, fracture load tests on crowns are performed although their significance is controversially discussed ${ }^{9-15}$. Due to differences in test set up, fracture load of restorative materials can vary significantly ${ }^{10-15)}$. Parameters such as crown design, core material, preparation form, loading angle as well as cementation procedures influence fracture load values.

Cementation with adhesive or self-adhesive composite resin cement increases fracture load values of crown materials with low internal strength ${ }^{14}$. A high compressive strength of the cement results in a homogeneous stress distribution and elevates the stability of the restorative system ${ }^{14)}$. The cement fills

Color figures can be viewed in the online issue, which is available at J-STAGE.

Received Apr 3, 2017: Accepted May 26, 2017

doi:10.4012/dmj.2017-111 JOI JST.JSTAGE/dmj/2017-111 the gap between crown and implant, thus preventing from preliminary contacts that might cause stress peaks followed by early crack growth. The manufacturing of crowns for fracture load tests is expensive and hard to standardize. Measurements on standardized, geometrical specimens as used for flexural strength or fracture toughness tests deliver reproducible results. Therefore, it is reasonable to establish correlations between fracture load values and mechanical data such as flexural strength and fracture toughness of restorative materials. Purpose of this study was to evaluate the fracture load of different zirconia implant supported monolithic crown materials cemented with various cements.

\section{MATERIALS AND METHODS}

Fracture load of 250 molar crowns of 5 different materials (Table 1) was measured on zirconia implants using no cement, temporary cement, self-adhesive cement or either one of 2 adhesive cements. Crown materials were characterized by flexural strength and fracture toughness. Additionally compressive strength of the cements was measured.

\section{Implants}

Ten one-piece implants (ceramic.implant, vitaclinical, VITA Zahnfabrik, Bad Säckingen, Germany) with a diameter of $4.0 \mathrm{~mm}$ were used in this study. For measuring fracture load values higher than $2,000 \mathrm{~N}$, 10 steel duplicates were manufactured to prevent the zirconia implants from chipping. The elastic modulus of steel (steel quality used was $1.4301 \mathrm{X}-10 \mathrm{Cr} \mathrm{Ni} 18 / 8$ with 
Table 1 Materials used

\begin{tabular}{|c|c|c|c|c|}
\hline & Code & Manufacturer & Lot No. & Type \\
\hline \multicolumn{5}{|l|}{ Crown materials } \\
\hline VITA YZ T & $\mathrm{YZ}$ & \multirow{4}{*}{$\begin{array}{l}\text { VITA Zahnfabrik, Bad } \\
\text { Säckingen, Germany }\end{array}$} & 37080 & Yttrium stabilized zirconia \\
\hline VITA In-Ceram AL & $\mathrm{AL}$ & & 26390 & Alumina \\
\hline VITABLOCS Mark II & $\mathrm{VM}$ & & 27291 & Feldspar ceramic \\
\hline VITA ENAMIC & VE & & 100001 & Polymer infiltrated feldspar ceramic \\
\hline IPS e.max CAD & EC & $\begin{array}{l}\text { Ivoclar Vivadent, } \\
\text { Schaan, Liechtenstein }\end{array}$ & N67622 & Lithium disilicate \\
\hline \multicolumn{5}{|l|}{ Cement materials } \\
\hline $\begin{array}{l}\text { Harvard Implant } \\
\text { semi-permanent }\end{array}$ & HIS & \multirow{2}{*}{$\begin{array}{l}\text { Harvard Dental } \\
\text { International, } \\
\text { Hoppegarten, Germany }\end{array}$} & 7206489 & temporary dual-cured cement \\
\hline Harvard LuteCem SE & HLC & & 7602914 & self-adhesive dual-cured cement \\
\hline Multilink Automix & MLA & Ivoclar Vivadent & S53599 & adhesive dual-cured cement \\
\hline VITA Adiva F-Cem & VAF & VITA Zahnfabrik & 17601812 & adhesive dual-cured cement \\
\hline
\end{tabular}

$200 \mathrm{GPa}$ ) is similar to the one of the zirconia implants as provided by the manufacturer $(210 \mathrm{GPa})$. The implants were embedded in epoxy (RenCast CW 20 / Ren HY 49, Huntsman Advanced Materials, Duxford, UK) according to ISO 14801: 2008.

\section{Crown manufacturing and cementation}

The test set-up has been previously described ${ }^{14)}$. Fifty molar crowns (tooth 46) of each material (Table 1) were manufactured using CAD/CAM processing (Omnicam and inLab MCXL, Sirona, Bensheim, Germany). Specimens of lithium disilicate were crystallized after the milling process (Vacumat 4000, VITA) as specified by the manufacturer. Zirconia and alumina crowns were grinded over dimensioned and sintered according to the manufacturers' recommendations (Zircomat 6000, VITA). All crowns were finally polished using a goat hair buffing wheel and polishing paste (Wetzler Dental, Bielefeld, Germany). Prior to cementation, crowns and implants were properly cleaned in an ultrasonic bath with 96\% ethanol for 5 min (TPC-15, Telsonic, Bronschhofen, Switzerland). Ten crowns of each restorative material were placed on the implant without cement and loaded until fracture. The remaining crowns were cemented with either temporary cement (HIS), selfadhesive cement (HLC) or adhesive cement (MLA/VAF) prior to loading $(n=10)$. No primers were applied. The crowns were filled with cement, placed on the implants and loaded with $20 \mathrm{~N}$ for $10 \mathrm{~min}$. Curing was performed exclusively by autopolymerization. Excess cement was eliminated using foam pellets. After the cementation process, the specimens were stored in distilled water at $37^{\circ} \mathrm{C}$ for $24 \mathrm{~h}$ (CTS T-4025, CTS, Hechingen, Germany).
Fracture load test

Ten specimens of each group were consecutively placed in a universal testing machine (Z020, Zwick/Roell, Ulm, Germany) and loaded until fracture. Fracture load test was performed at a crosshead speed of $1 \mathrm{~mm} / \mathrm{min}$. A steel ball (4.75 $\mathrm{mm}$ diameter) was adjusted in the center of the occlusal surface on top of a $0.2 \mathrm{~mm}$ thick tin foil (Dentaurum, Pforzheim, Germany) to attain a homogenous stress distribution (Fig. 1). The fracture load values were recorded (testXpert V 2.2, Zwick/ Roell). After the fracture load test the implants were carefully cleaned and re-used for the subsequent test series. Remaining cement on the implant abutment was completely removed using a blow-dryer at $200^{\circ} \mathrm{C}(\mathrm{MZ} 6$ HL, miolectric, Zurich, Switzerland).

\section{Fracture Analysis}

Two randomly selected specimens of each group were analyzed after fracture using SEM (Philips XL30 FEG ESEM, Philips Electron Optics, Eindhoven, The Netherlands).

\section{Compressive strength of cements}

Compressive strength of the cements (Table 1) was measured with cylindrical test specimens $3 \mathrm{~mm}$ in height and diameter $(n=10)$. A Teflon mold (Distrelec, Nänikon, Switzerland) was used to produce the test specimens. The cement was filled into the respective cavities of the Teflon mold and kept in place with a plastic foil and a glass plate on each side. After $1 \mathrm{~h}$ storage in distilled water at $37^{\circ} \mathrm{C}$ the specimens were carefully removed from the mold and stored in water at $37^{\circ} \mathrm{C}$ for another $24 \mathrm{~h}$. No light curing was performed. Specimens were loaded parallel to the cylinder axis until fracture (Z020, Zwick/Roell). 


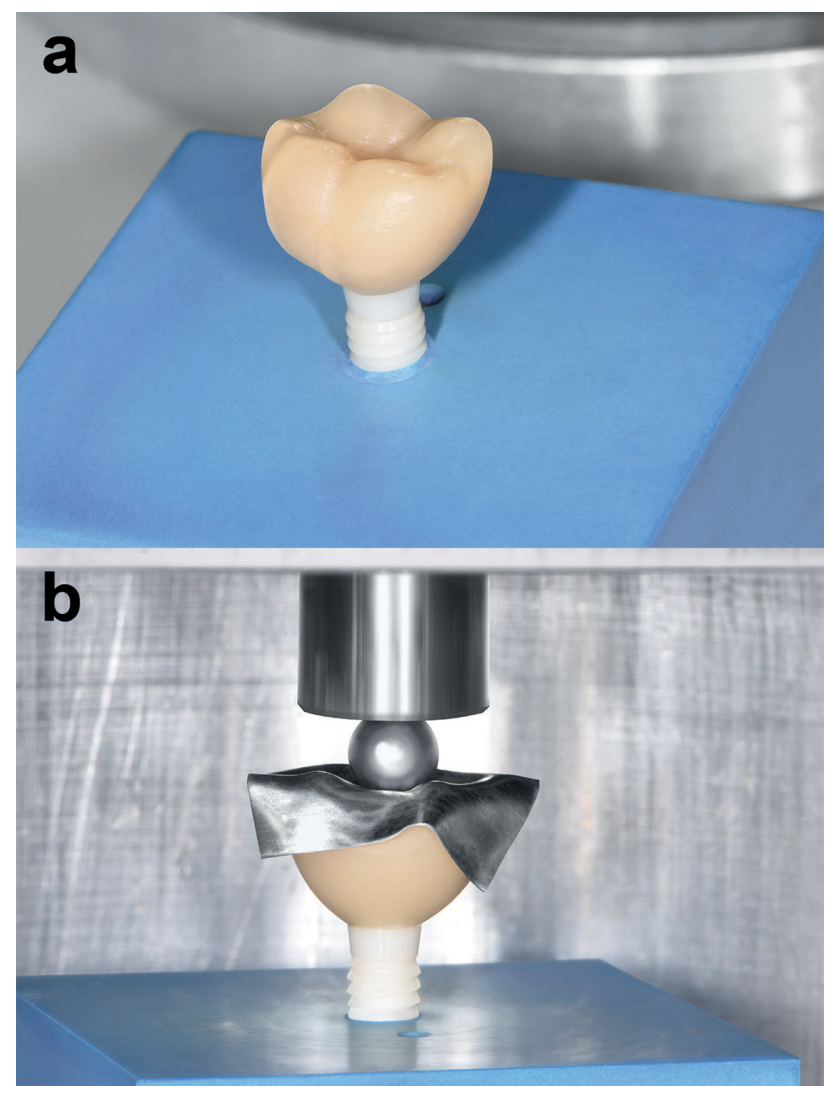

Fig. 1 Test set-up of the fracture load test.

a) cemented crown on zirconia implant, b) A tin foil and a steel ball were placed on the crown when loaded until fracture.

The following equation was used to calculate compressive strength:

$$
\sigma_{\mathrm{c}}=\mathrm{F} /(\mathrm{nd})
$$

$\sigma_{\mathrm{c}}$ is the compressive strength; $\mathrm{F}$ is the fracture load; $\mathrm{d}$ is the diameter.

\section{Flexural strength of crown materials}

Flexural strength of the crown materials was determined using the 3-point bending test design. Ten bending bars of each crown material with a dimension of $3 \times 4 \times 20$ $\mathrm{mm}$ were produced out of CAD/CAM blocs. Specimens of $\mathrm{VE}$ and VM were manually grinded with silica paper (P1200) to the final dimensions. EC specimens were lapped with D15 (MDF 400 PR, Bierther Submikron, Bad Kreuznach, Germany) and crystallized (Vacumat 4000, VITA). YZ and AL specimens were cut over dimensioned, grinded (D91; FSM 480 A, Knuth, Wasbek, Germany) and sintered according to the manufacturers' recommendations (Vacumat 6000, VITA). Edges of the specimens were chamfered according to ISO 6872. Three point bending test was performed with a universal testing machine (Z020 Zwick/Roell) at a crosshead speed of $0.5 \mathrm{~mm} / \mathrm{min}$ until fracture. Flexural strength $\sigma$ was calculated using the following formula:

$$
\sigma=3 \mathrm{Fl} / 2 \mathrm{wh}^{2}
$$

$\mathrm{F}$ is the fracture load; $\mathrm{l}$ is the roller span (here 15 $\mathrm{mm})$; $\mathrm{w}$ is the width and $\mathrm{h}$ is the height of the bar.

\section{Fracture toughness of crown materials}

Fracture toughness was measured according to ISO 6872: 2015. Another 5 bending bars of each crown material were produced as described above. The bars were notched in the middle with a $250 \mu \mathrm{m}$ cut using a razor blade and diamond suspension of $3 \mu \mathrm{m}$. Specimens were loaded until fracture (Z010 Zwick/Roell) at a crosshead speed of $0.5 \mathrm{~mm} / \mathrm{min}$. Fracture toughness $\mathrm{K}_{\mathrm{Ic}}$ was calculated according to ISO CEN/TS 14425-5: 2004 using the following formula:

$$
\begin{aligned}
\mathrm{K}_{\mathrm{Ic}}=\mathrm{Y}(\mathrm{F} /(\mathrm{w} \sqrt{\mathrm{h}}))(\mathrm{l} / \mathrm{h})(3 \sqrt{\alpha(2(1-\alpha) 1.5)}) \\
\mathrm{Y}=1.9472-5.0247 \alpha+11.8954 \alpha^{2}-18.0635 \alpha^{3}+14.5986 \alpha^{4} \\
\quad-4.6896 \alpha^{5} \\
\alpha=\mathrm{a} / \mathrm{h}
\end{aligned}
$$

$\mathrm{F}$ is the fracture load; $\mathrm{w}$ and $\mathrm{h}$ are bending bar width and height, $l$ is the roller span $(15 \mathrm{~mm})$, a is the notch depth $(250 \mu \mathrm{m})$ and $\mathrm{Y}$ is the stress intensity shape factor.

\section{Statistical analysis}

Data was tested for normal distribution with ShapiroWilk test. One-way ANOVA $(p>0.05)$ was applied to each testing method to test for differences between the materials. Comparisons between groups were evaluated using Fisher LSD test (statplus Version V6).

\section{RESULTS}

\section{Fracture load}

The crowns fractured at loads ranging from 260 to 4,550 N (Table 2). Data was normal distributed; hence oneway ANOVA test and Fisher LSD test were applied. For lithium disilicate (EC), polymer-infiltrated ceramic (VE) and feldspar ceramic (VM) highest fracture load values within the respective material class were achieved with adhesive cement with high compressive strength (VAF and MLA). For EC, VE and VM statistical significant differences were found between all cement groups except between the cementation with adhesive cements MLA and VAF (EC: $p=0.183$; VE: $p=0.451$; VM: $p=0.293$ ). Statistical significant lowest values within these materials were recorded when measuring without cement $(p<0.001)$. For oxide ceramics the various cements had no significantly different effect on the fracture load values (YZ: $p=0.726$; AL: $p=0.964$ ).

During pre-tests chipping fractures occurred at the implant shoulders of zirconia implants when loaded higher than $2,000 \mathrm{~N}$. That was the reason to test EC, AL and ZR crowns on steel replica.

All crowns fractured in 2-5 fragments. No correlation 
Table 2 Fracture load means and standard deviations for all crown materials depending on the cement used

\begin{tabular}{lccccc}
\hline \multicolumn{1}{c}{$(\mathrm{N})$} & YZ & AL & EC & VE & VM \\
\hline no cement & $4,550(58)^{\mathrm{A}, \mathrm{a}}$ & $2,717(511)^{\mathrm{B}, \mathrm{a}}$ & $998(227)^{\mathrm{C}, \mathrm{a}}$ & $506(154)^{\mathrm{C}, \mathrm{D}, \mathrm{a}}$ & $260(52)^{\mathrm{D}, \mathrm{a}}$ \\
HIS & $4,502(791)^{\mathrm{A}, \mathrm{a}}$ & $2,691(629)^{\mathrm{B}, \mathrm{a}}$ & $1,237(108)^{\mathrm{C}, \mathrm{b}}$ & $871(40)^{\mathrm{C}, \mathrm{D}, \mathrm{b}}$ & $683(117)^{\mathrm{D}, \mathrm{b}}$ \\
HLC & $4,496(392)^{\mathrm{A}, \mathrm{a}}$ & $2,721(477)^{\mathrm{B}, \mathrm{a}}$ & $1,482(238)^{\mathrm{C}, \mathrm{c}}$ & $1,053(122)^{\mathrm{D}, \mathrm{c}}$ & $871(129)^{\mathrm{D}, \mathrm{c}}$ \\
MLA & $4,520(413)^{\mathrm{A}, \mathrm{a}}$ & $2,657(367)^{\mathrm{B}, \mathrm{a}}$ & $1,780(200)^{\mathrm{C}, \mathrm{d}}$ & $1,253(148)^{\mathrm{D}, \mathrm{d}}$ & $1,091(117)^{\mathrm{D}, \mathrm{d}}$ \\
VAF & $4,510(315)^{\mathrm{A}, \mathrm{a}}$ & $2,721(286)^{\mathrm{B}, \mathrm{a}}$ & $1,798(297)^{\mathrm{C}, \mathrm{d}}$ & $1,297(150)^{\mathrm{D}, \mathrm{d}}$ & $1,042(88)^{\mathrm{E}, \mathrm{d}}$ \\
\hline
\end{tabular}

Values for VE and VM with no cement, HIS and MLA are obtained from Ref. 14. Statistical similar groups are marked with superscript letters (uppercase horizontal, lowercase vertical comparison).
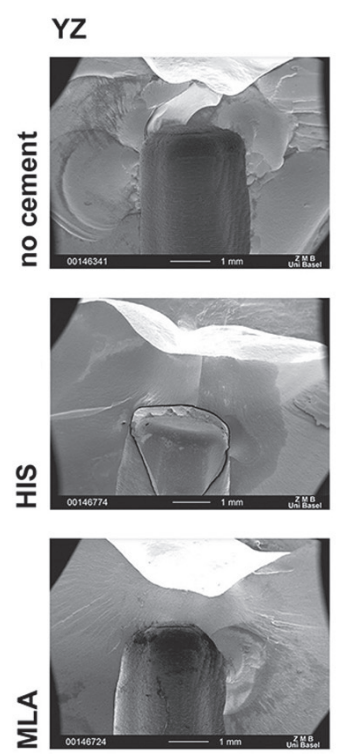

AL
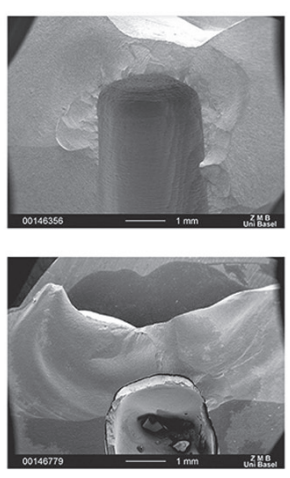

EC
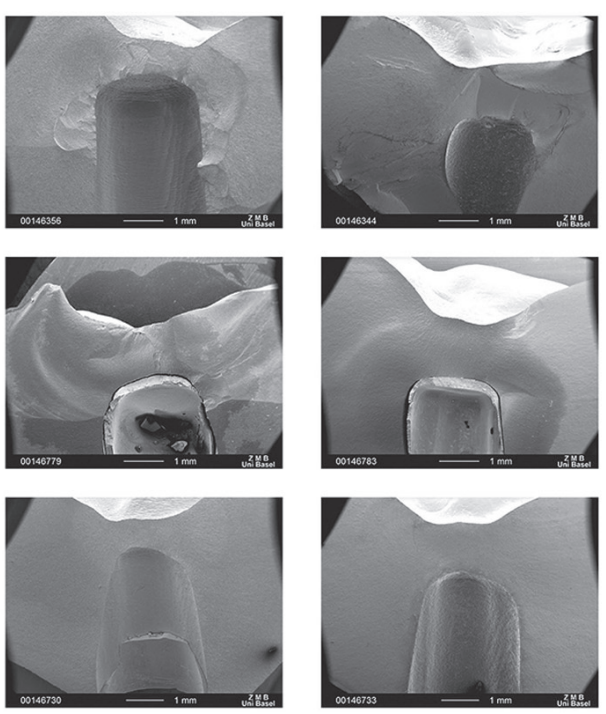

VE
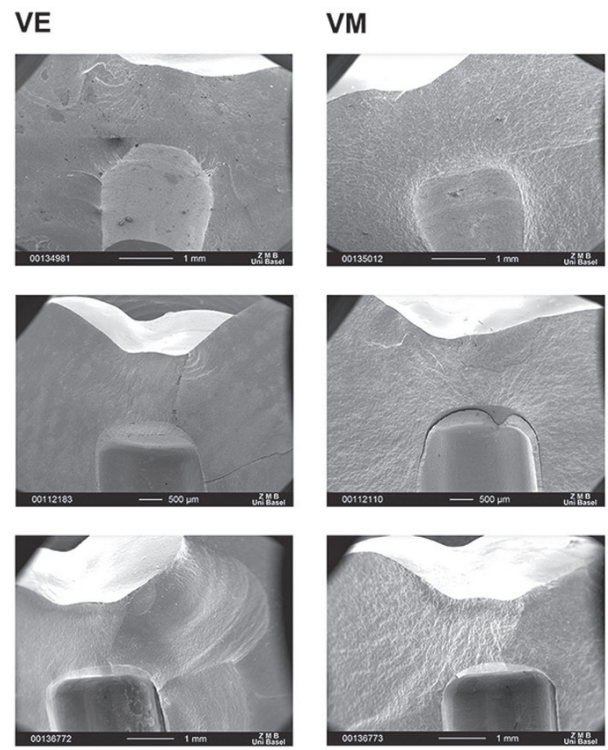

Fig. 2 SEM images of fractured crowns for no cement, HIS and MLA material (17-20×).

For uncemented crowns the initial fracture started from the implant side, for cemented crowns rather from the loading point. The direction of crack propagation can be identified by fine hackle radiating outward.

was found between the number of fragments and the material combinations. Fracture patterns were initiated for most specimens from both the occlusal loading point and the intaglio surface at the top of the implant abutment. For uncemented crowns the initial fracture started from the implant side, for cemented crowns rather from the loading point. In Fig. 2 SEM images of fractured crowns are presented for no cement, HIS and MLA. Fracture patterns for HLC and VAF were similar to MLA and are therefore not displayed.

\section{Compressive strength of the cements}

Compressive strength of the adhesive cements VAF (372.4 $\pm 33.0 \mathrm{MPa})$ and MLA $\left(321.0 \pm 9.3 \mathrm{MPa}^{14)}\right)$ differed significantly $(p<0.001)$. HLC $(213.9 \pm 34.1 \mathrm{MPa})$ was significantly $(p<0.001)$ lower than VAF and MLA. The temporary cement achieved lowest values (HIS: $37.1 \pm 7.0$ $\left.\mathrm{MPa}^{14)}\right)$. Without cement the compressive strength was set to 0 .

\section{Flexural strength of crown materials}

All flexural strength values for each material varied significantly from each other (Table 3). Highest flexural strength was recorded for zirconia (YZ: 1,174.8 \pm 109.1 $\mathrm{MPa}$ ), lowest for feldspar ceramic (VM: 128.0 \pm 11.9 $\mathrm{MPa})$.

\section{Fracture toughness of crown materials}

Fracture toughness values for zirconia (YZ), alumina (AL) and lithium disilicate (EC) differed significantly (Table 3) from each other and from VM and VE. No statistical difference was found between fracture toughness of feldspar (VM) and polymer-infiltrated ceramic (VE) $(p=0.962)$.

Correlation between fracture load and compressive strength of cement

For lithium disilicate (EC), feldspar ceramic (VM) and polymer-infiltrated ceramic (VE) an increase in fracture 
Table 3 Means and standard deviation of flexural strength and fracture toughness of crown materials

\begin{tabular}{lccccc}
\hline & YZ & AL & EC & VM & VE \\
\hline Flexural strength $\sigma(\mathrm{MPa})$ & $1,174.8(109.1)^{\mathrm{A}}$ & $579.4(38.7)^{\mathrm{B}}$ & $402.6(50.0)^{\mathrm{C}}$ & $128.0(11.9)^{\mathrm{D}}$ & $143.0(12.1)^{\mathrm{E}}$ \\
Fracture toughness $\mathrm{K}_{\mathrm{Ic}}(\mathrm{MPa} \sqrt{\mathrm{m}})$ & $8.93(1.91)^{\mathrm{A}}$ & $4.51(0.19)^{\mathrm{B}}$ & $2.74(0.28)^{\mathrm{C}}$ & $1.23(0.06)^{\mathrm{D}}$ & $1.26(0.05)^{\mathrm{D}}$ \\
\hline
\end{tabular}

Statistical similar groups are marked with superscript letters between crown materials.

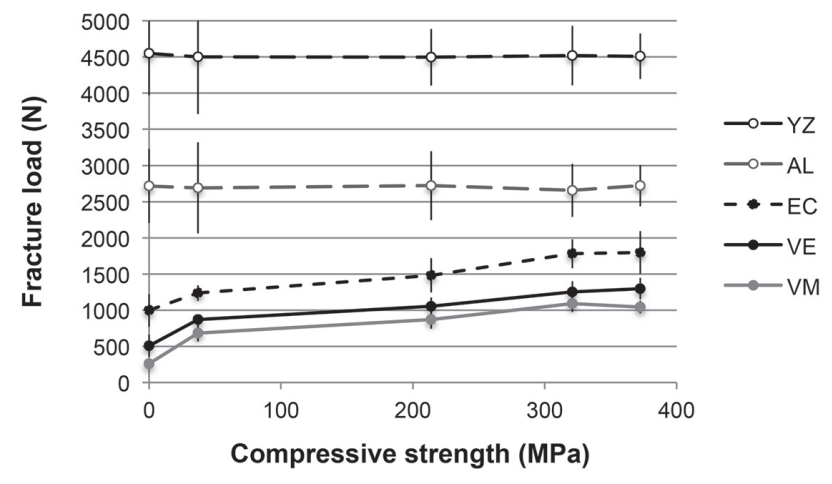

Fig. 3 Correlation between fracture load of crown materials and compressive strength of the cements (means).

Values for compressive strength of HIS and MLA and fracture load VE und VM without cement, HIS and MLA are obtained from Ref. 14.

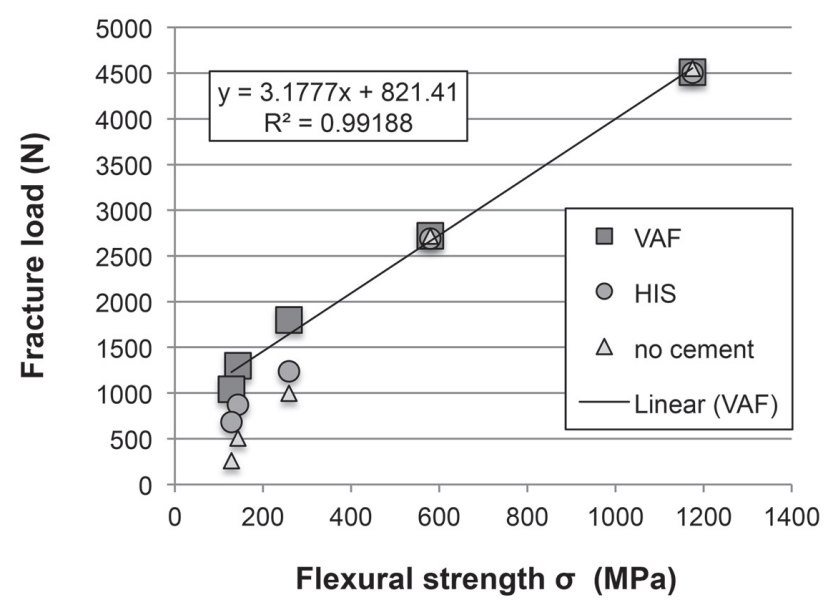

Fig. 4 Correlation between the fracture load of crowns and the flexural strength of the respective material.

load values was detected with increasing compressive strength of the cement. From MLA to VAF the fracture load values were only slightly increased, resulting in a saturation curve. The resulting curves for EC, VE and VM are running in parallel (Fig. 3). For oxide ceramics (YZ, AL) compressive strength of the cements did not influence the fracture load.

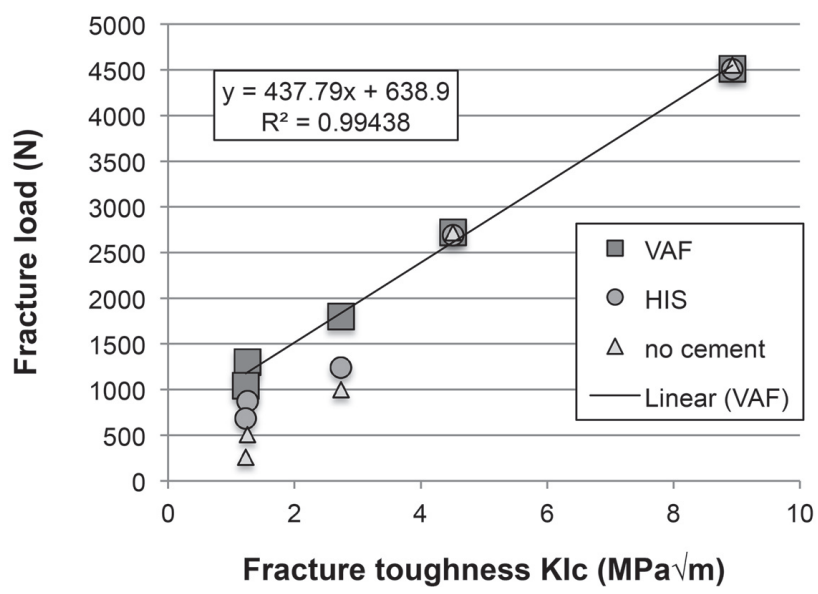

Fig. 5 Correlation between the fracture load of crowns and the fracture toughness of the respective material.

Correlation between fracture load and flexural strength of crown materials

A linear correlation between fracture load and flexural strength of the respective restorative ceramic material was found when crowns were cemented with adhesive cement (MLA, VAF), i.e. the cement with a compressive strength above $320 \mathrm{MPa}$ (Fig. 4).

Correlation between fracture load and fracture toughness of crown materials

An even stronger correlation was found between fracture load and fracture toughness of the respective ceramic material (Fig. 5). To improve the outline of Figs. 4 and 5 only values for no cement, HIS and VAF are displayed.

\section{DISCUSSION}

Purpose of this study was to evaluate the fracture load of different zirconia implant supported monolithic crown materials cemented with various cements. An increased compressive strength of the cements increased the fracture load for lithium disilicate (EC), feldspar (VM) and polymer-infiltrated ceramic (VE). For oxide ceramics (AL, YZ) fracture load values were not influenced by the type of cement. Linear correlations were found between the crowns cemented with adhesive cement with high compressive strength and the flexural strength as well as the fracture toughness of the crown materials. 


\section{Fracture load test design}

Clinically crown fractures are mainly caused by subcritical crack growth, which is due to small, constant, dynamic forces that are applied on the restoration over time ${ }^{16)}$. In this study crowns were fractured with high static loads. Therefore, the initial crack growth might differ from a clinical situation. Light curing of the cement was not performed. Additional light-curing can increase the properties of the cements ${ }^{17}$. In a clinical situation light-curing cannot always be sufficiently performed. Hence, it was decided to cure by autopolymerization. The specimens in the present test design were stored for $24 \mathrm{~h}$ in $37^{\circ} \mathrm{C}$ water before loading to fracture. In the oral cavity restoration, cement and implant are exposed to a constant humid environment including temperature changes and chewing forces over years. Therefore in future studies the effect of aging and cyclic loading on the fracture load has to be further investigated.

Despite these limitations the present study revealed important findings on the influence of the compressive strength of the cement on the overall stability of the reconstruction.

\section{Influence of the cement on the fracture load}

It is known that the type of cement can influence the fracture load for materials with a low intrinsic strength $^{13,14)}$. For glass ceramics (IPS Empress CAD) an increase in fracture load was recorded ${ }^{13)}$ when cemented with self-adhesive cement compared to the situation where no cement was applied, which confirms the results of the present study. In the same study no difference was found in fracture load values between different cementation processes for zirconia ${ }^{13)}$. The influence of the cementation mode on lithium disilicate is controversially discussed ${ }^{12,13)}$. In the present study an increase in fracture load was found for lithium disilicate, feldspar ceramic and polymer-infiltrated ceramic depending on the compressive strength of the cement. An optimal support of a restoration (EC, VE, $\mathrm{VM})$ is achieved when resin composite cement with a compressive strength above $320 \mathrm{MPa}$ (MLA, VAF) is used. The manufacturer of lithium disilicate cleared the material for conventional cementation. Clinically it has been shown that there is no influence of the survival rate of lithium disilicate crowns if they are cemented with conventional or adhesive cement ${ }^{18)}$. However, to use the full potential of lithium disilicates' material properties, cementation with adhesive cement is recommended. The more stable the cement the better it seems to reduce stress peaks between implant and crown. VE and VM do not offer the option of conventional cementation. The fracture load of oxide ceramics (AL, YZ) is not influenced by the cement due to the high intrinsic strength of the material confirming previous findings for $\mathrm{YZ}^{13,19)}$. Fracture analysis revealed for cemented crowns an initial fracture start from the loading point. Fracture for uncemented specimens started from the implant side, suggesting that direct contact of crown and implant triggered the crack initiation.

The fracture load test therefore is reasonable regarding the assessment of the complete restoration system. Fracture load tests deliver first hints on the strength of a restorative material that is required to have free choice for cementing with conventional or adhesive cement.

Correlation between fracture load, flexural strength and fracture toughness

The obtained values for flexural strength for EC $(402.6 \pm 50.0 \mathrm{MPa})$ and $\mathrm{VE}(143.0 \pm 12.1 \mathrm{MPa})$ are in the range of previous findings for lithium disilicate $\left(356.7 \pm 59.6 \mathrm{MPa}^{20)}, 376.9 \pm 76.2 \mathrm{MPa}^{21)}\right)$ and polymerinfiltrated ceramic (135.8 $\pm 8.3 \quad \mathrm{MPa}^{20)}, \quad 202.1 \pm 17.9$ $\left.\mathrm{MPa}^{21)}\right)$. The fracture toughness values for EC $(2.74 \pm 0.28 \mathrm{MPa} \sqrt{\mathrm{m}})$ and $\mathrm{VE}(1.26 \pm 0.05 \mathrm{MPa} \sqrt{\mathrm{m}})$ were also in accordance with previous studies where fracture toughness of lithium disilicate $(2.8 \pm 0.1 \mathrm{MPa} \sqrt{\mathrm{m}})^{20)}$ and polymer-infiltrated ceramic $(1.4 \pm 0.1 \mathrm{MPa} \sqrt{\mathrm{m}})^{20)}$ was recorded using the SEVNB method. In the present study a linear correlation between flexural strength and fracture toughness was derived for the tested dental ceramics. The V-shaped fissures of the molar crowns used might have had a similar effect on the fracture load as the notch-technique used for the SEVNB method for determining fracture toughness.

Further, a linear correlation between fracture load of ceramic crown materials with adhesive cement (MLA, VAF) and flexural strength was found. These findings stand in contrast to those found in another study where crowns of various ceramic, composite or polymer materials were cemented on steel implant replicas with only one cement (RelyX Ultimate) the flexural strength of the crown materials and the fracture load did not correlate $^{22)}$. This might be due to the variety of the tested material groups (ceramic, composite, polymer) that also differ in their fracture behavior that may result in different correlations for each material group. Also, the cement that was applied might not have supported the crowns sufficiently to achieve their full material potential.

\section{Clinical relevance}

Over one year, zirconia implants attained survival results similar to traditional two-piece titanium implants $^{4,23)}$. However, zirconia implants that were restored with veneered zirconia displayed a severe chipping rate of the restorations between 42.8 and $62 \%$ for single crowns and FDPs after an observation period of 5 years ${ }^{5)}$. Another study reported chipping fractures of the veneering ceramic of zirconia in $9.1 \%$ of the investigated posterior single crowns after an observation period of 1 year ${ }^{23)}$. Monolithic approaches might be able to circumvent surface deterioration of veneering ceramics ${ }^{15,23)}$. Clinical results for lithium disilicate on zirconia implants seem promising ${ }^{2)}$. Due to their brittleness, zirconia implants react more sensible on tensile stress than titanium implants. To prevent chipping of the crowns or the implant shoulder, polymerinfiltrated ceramic might therefore be the better choice to restore implants than a material with a high elastic 
modulus such as silicate or oxide ceramic. The impact of the elastic modulus of the restorative material on the bone level has to be clinically assessed.

Chipping on the implant shoulder that was found in this study occurred at forces over 2,000 N. It has to be acknowledged that such high forces do not stand in any relation to maximum oral chewing forces of $600-1,200$ $\mathrm{N}^{24)}$.

In order to achieve sufficient fracture load values, cementation with adhesive cement with high compressive strength is essential for feldspar and polymer-infiltrated ceramic. Lithium disilicate and oxide ceramics revealed fracture load values with temporary cement in this test design that were able to withstand maximum intraoral chewing forces in the molar region ${ }^{24}$. To use the full potential of lithium disilicates' material properties on zirconia implants, adhesive cementation is recommended although the material is cleared for conventional cementation

\section{CONCLUSIONS}

Within the limitations of this study it can be concluded that:

1. Highest fracture loads of zirconia implant supported single crowns fabricated from lithium disilicate, feldspar or polymer-infiltrated ceramic are achieved when adhesive resin composite cement with a compressive strength above 320 $\mathrm{MPa}$ is applied.

2. The fracture load of zirconia implant supported single crowns fabricated from zirconia and alumina is not affected by the cement.

3. The fracture load of monolithic ceramic restorations cemented with adhesive resin composite cement is linearly correlated with the flexural strength and the fracture toughness of the respective ceramic.

4. Fracture load tests with zirconia implant supported single crowns provide information on the mechanical performance of the respective combination of crown material and cement.

\section{ACKNOWLEDGMENTS}

The authors would like to thank VITA Zahnfabrik for supporting this study with materials.

\section{REFERENCES}

1) Osman R, Swain M. A critical review of dental implant materials with an emphasis on titanium versus zirconia. Materials 2015; 8: 932-958.

2) Spies BC, Patzelt SB, Vach K, Kohal RJ. Monolithic lithiumdisilicate single crowns supported by zirconia oral implants: three-year results of a prospective cohort study. Clin Oral Implants Res 2015; 17: 1014-1028.

3) Gahlert M, Burtscher D, Pfundstein G, Grunert I, Kniha $\mathrm{H}$, Roehling S. Dental zirconia implants up to three years in function: a retrospective clinical study and evaluation of prosthetic restorations and failures. Int J Oral Maxillofac Implants 2013; 28: 896-904.
4) Jung RE, Grohmann P, Sailer I, Steinhart YN, Féher A, Hämmerle C, Strub JR, Kohal R. Evaluation of a one-piece ceramic implant used for single-tooth replacement and threeunit fixed partial dentures: a prospective cohort clinical trial. Clin Oral Implants Res 2016; 27: 751-761.

5) Pieralli S, Kohal RJ, Jung RE, Vach K, Spies BC. Clinical outcomes of zirconia dental implants: A systematic review. J Dent Res 2017; 96: 38-46.

6) Hashim D, Cionca N, Courvoisier DS, Mombelli A. A systematic review of the clinical survival of zirconia implants. Clin Oral Investig 2016; 20: 1403-1417.

7) Spies BC, Stampf S, Kohal RJ. Evaluation of zirconiabased all-ceramic single crowns and fixed dental prosthesis on zirconia implants: 5-year results of a prospective cohort study. Clin Implant Dent Relat Res 2015; 17: 1014-1028.

8) Coldea A, Swain MV, Thiel N. Hertzian contact response and damage tolerance of dental ceramics. J Mech Behav Biomed Mater 2014; 34: 124-133.

9) Zhang Y, Sailer I, Lawn BR. Fatigue of dental ceramics. J Dent 2013; 41: 1135-1147.

10) Burke FJ, Watts DC. Fracture resistance of teeth restored with dentin-bonded crowns. Quintessence Int 1994; 25: 335340.

11) Attia A, Abdelaziz KM, Freitag S, Kern M. Fracture load of composite resin and feldspathic all-ceramic CAD/CAM crowns. J Prosthet Dent 2006; 95: 117-123.

12) Borges GA, Caldas D, Taskonak B, Yan J, Sobrinho LC, de Oliveira WJ. Fracture loads of all-ceramic crowns under wet and dry fatigue conditions. J Prosthodont 2009; 18: 649-655.

13) Stawarczyk B, Beuer F, Ender A, Roos M, Edelhoff D, Wimmer T. Influence of cementation and cement type on the fracture load testing methodology of anterior crowns made of different materials. Dent Mater J 2013; 30: 888-895.

14) Rohr N, Coldea A, Zitzmann NU, Fischer J. Loading capacity of implant supported hybrid ceramic crowns. Dent Mater 2015; 31: e279-288.

15) Kohal RJ, Kilian JB, Stampf S, Spies BC. All-ceramic single crown restauration of zirconia oral implants and its influence on fracture resistance: An investigation in the artificial mouth. Materials 2015; 8: 1577-1589.

16) Zhu Q, de With G, Dortmans LJ, Feenstra F. Subcritical crack growth behavior of Al2O3-glass dental composites. J Biomed Mater Res B Appl Biomater 2003; 15: 233-238.

17) Ilie N, Simon A. Effect of curing mode on the micro-mechanical properties of dual-cured self-adhesive resin cements. Clin Oral Investig 2011; 16: 505-512.

18) Gehrt M, Wolfart S, Rafai N, Reich S, Edelhoff D. Clinical results of lithium-disilicate crowns after up to 9 years of service. Clin Oral Investig 2013; 17: 275-284.

19) Nakamura K, Mouhat M, Nergård JM, Lægreid SJ, Kanno T, Milleding P, Örtengren U. Effect of cements on fracture resistance of monolithic zirconia crowns. Acta Biomater Odontol Scand 2016; 2: 12-19.

20) Homaei E, Farhangdoost K, Tsoi JK, Matinlinna JP, Pow EH. Static and fatigue mechanical behavior of three dental CAD/ CAM ceramics. J Mech Behav Biomed Mater 2016; 59: 304313.

21) Lawson NC, Bansal R, Burgess JO. Wear, strength, modulus and hardness of CAD/CAM restorative materials. Dent Mater 2016; 32: e275-e283.

22) de Kok P, Kleverlaan CJ, de Jager N, Kuijs R, Feilzer AJ. Mechanical performance of implant-supported posterior crowns. J Prosthet Dent 2015; 114: 59-66.

23) Spies BC, Kohal RJ, Balmer M, Vach K, Jung RE. Evaluation of zirconia-based posterior single crowns supported by zirconia implants: preliminary results of a prospective multicenter study. Clin Oral Implants Res 2017; 28: 613-619.

24) Peck CC. Biomechanics of occlusion -implications for oral rehabilitation. J Oral Rehabil 2016; 43: 205-214. 